\title{
The Impact of the "Muslim Ban" Executive Order on Healthcare Utilization in Minneapolis-St. Paul, Minnesota
}

Elizabeth A. Samuels, MD, MPH, MHS ${ }^{1}$, Lilla Orr, MA², Elizabeth B. White, BA ${ }^{3}$, Altaf Saadi, MD, MHS ${ }^{4}$, Aasim I. Padela, MD, MSc ${ }^{5}$, Michael Westerhaus, MD, MA ${ }^{6}$, Aarti D. Bhatt, MD $^{7}$, Pooja Agrawal, MD, $\mathrm{MPH}^{8}$, Dennis Wang, $\mathrm{MD}, \mathrm{MPH}^{9}$, Gregg Gonsalves, $\mathrm{PhD}^{2}$

${ }^{1}$ Department of Emergency Medicine, Alpert Medical School of Brown University, Providence, RI

${ }^{2}$ Department of Political Science, Yale University, New Haven, CT

${ }^{3}$ Department of Epidemiology of Microbial Diseases, Yale School of Public Health, New Haven, CT

${ }^{4}$ Department of Neurology, Massachusetts General Hospital, Boston, MA

${ }^{5}$ Section of Emergency Medicine, Department of Medicine, University of Chicago, Chicago, IL

${ }^{6}$ HealthPartners Center for International Health, Minneapolis, MN

${ }^{7}$ Division of General Internal Medicine, University of Minnesota, Minneapolis, MN

${ }^{8}$ Department of Emergency Medicine, Yale School of Medicine, New Haven, CT

${ }^{9}$ Yale School of Medicine, New Haven, CT

\begin{abstract}
Objective: Determine whether the 2017 "Muslim Ban" Executive Order impacted healthcare utilization by people born in Order-targeted nations living in the United States.

Methods: We conducted a retrospective cohort study of people living in Minneapolis-St. Paul, MN in 2016-2017 who were: 1) born in Order-targeted nations, 2) born in Muslim-majority nations not listed in the Order, and 3) born in the United States and non-Latinx. Primary outcomes were: 1) primary care visits, 2) missed primary care appointments, 3) primary care diagnoses for stress-responsive conditions, 4) emergency department visits, and 5) emergency department visits for stress-responsive diagnoses. We evaluated visit trends before and after Order issuance using linear regression and differences between study groups using a differencein-difference analyses.
\end{abstract}

Results: In early 2016, primary care visits and stress-responsive diagnoses increased among individuals from Muslim majority nations. Following the Order, there was an immediate increase in emergency department visits among individuals from Order-targeted nations.

Conclusions: Increases in healthcare utilization among people born in Muslim majority countries before and after the "Muslim Ban" likely reflect elevated cumulative stress including the impact of the Order. 


\section{INTRODUCTION}

42 The 2016 United States (U.S.) presidential election was marked by anti-Muslim and anti-

43 immigrant rhetoric and the subsequent Trump administration has introduced multiple restrictive

44 immigration policies, primarily targeting individuals from Muslim-majority and Latin American

45 countries. ${ }^{1}$ On January 27, 2017, one week after taking office, President Trump issued Executive

46 Order 13769, "Protecting the Nation from Foreign Terrorist Entry into the United States,"2

47 commonly referred to as the "Muslim Ban." The Order, upheld by the U.S. Supreme Court, ${ }^{3}$

48 suspended the U.S. Refugee Resettlement Program and prevented citizens from seven Muslim-

49 majority countries (Iraq, Syria, Iran, Libya, Somalia, Sudan, and Yemen) from traveling or

50 immigrating to the U.S.

51 Policies like the Muslim Ban exacerbate heightened levels of discrimination, hostility, and

52 "othering" that U.S. Muslims experience. ${ }^{4}$ Over the past two decades there has been an increase

53 in hate crimes ${ }^{5}$ and social hostility ${ }^{6,7}$ directed toward U.S. Muslims, experiences which

54 negatively impact health. Following the September $11^{\text {th }}$ attacks, Arab Americans, including

55 Muslim Arab Americans, demonstrated increased rates of anxiety, depression, and low birth

56 weights. ${ }^{4,8-11}$ However, it is unknown how health and healthcare utilization in other Muslim

57 American communities have changed in response to shifting sociopolitical climates.

58 This study examines the impact of the Muslim Ban Order on healthcare utilization among

59 people from Order-targeted nations. We sought to determine whether the policy resulted in

60 avoidance of care due to fear of discrimination, or, as was seen among Arab Americans after

61 September $11^{\text {th }}$, increased healthcare utilization for stress-responsive medical problems. To

62 evaluate these changes, we examined primary care and emergency department (ED) utilization 
63 by people from Order-targeted nations living in the Minneapolis-St. Paul, Minnesota

64 metropolitan area, home to the largest Somali Muslim community in the U.S. ${ }^{12}$

\section{METHODS}

\section{Study Design}

68 We conducted a retrospective cohort study comparing changes in primary care and ED

69 utilization, missed scheduled clinic appointments, and visits for stress-responsive conditions

70 among individuals from Order-targeted nations from one year before to one year after Order

71 issuance. We characterized visit trends and, for outcomes with similar group trends prior to

72 Order issuance, used a difference-in-difference analysis to estimate its effects on healthcare

73 utilization. The primary analysis compared people born in one of the Order-targeted nations to

74 non-Latinx U.S.-born citizens. Supplementary analyses compared trends among people born in a

75 Muslim-majority nation not listed in the Order (Table 1, Group 2) to non-Latinx U.S.-born

76 citizens.

78 Study setting and population

79 The Minneapolis-St. Paul metropolitan area has 3.63 million residents and the largest Somali

80 Muslim population in the U.S. In 2017, three quarters (75.1\%) of Minneapolis-St. Paul

81 metropolitan area residents were white, $8.56 \%$ Black, and 6.64\% Asian. ${ }^{13}$ Approximately $10.2 \%$

82 of residents were born outside of the U.S., with an estimated 37,468 people born in Somalia. ${ }^{13}$

83 We analyzed electronic health record (EHR) data from HealthPartners, one of the area's

84 largest healthcare and insurance organizations, serving over 1.2 million patients at 55 primary

85 care centers, 22 acute care centers, and eight hospitals in the Minneapolis-St. Paul metropolitan 
86 area. While religion is not recorded in the EHR, patient country of origin recorded in the

87 HealthPartners EHR allowed us to characterize patients receiving care between January 1, 2016

88 and December 31, 2017 into three groups: 1) adults born in one of the seven nations mentioned

89 in the Muslim Ban Order (Iran, Iraq, Libya, Somalia, Sudan, Syria, and Yemen) (Table 1, Group

90 1), 2) adults born in Muslim-majority nations not listed in the Order (Table 1, Group 2), and 3)

91 U.S.-born non-Latinx adults (Table 1, Group 3). We excluded U.S.-born Latinx patients as they

92 have been subject to distinct anti-immigrant rhetoric and policies which have important impacts

93 on their health and healthcare utilization. ${ }^{14,15}$

\section{Outcomes}

96 We examined changes in primary care and ED utilization in the year before and after Order

97 issuance. Primary outcomes included the number of 1) primary care clinic visits, 2) missed

98 primary care clinic appointments, 3) primary care clinic diagnoses for stress-responsive

99 conditions, 4) ED visits, and 5) ED visits for stress-responsive diagnoses, including ambulatory

100 sensitive conditions. This study was conducted in accordance with STROBE guidelines and

101 approved by the HealthPartners and Yale Institutional Review Boards. ${ }^{16}$

103 Primary Care Clinic Utilization. Primary care visits, missed appointments, and stress-responsive

104 diagnoses were analyzed as counts per person. We identified stress-responsive diagnoses,

105 medical diagnoses that may be related to increased stress, through literature review and expert

106 opinion. ${ }^{10,14,17-23}$ Diagnoses included in the analysis were agreed upon by consensus (Table S1)

107 and included 138 ICD-10 codes grouped into six categories: mental health, sleep disorders,

108 gastrointestinal concerns, neurologic concerns, food-related disorders, and pain syndromes. 
110 Emergency Department Utilization. ED visits, stress-responsive diagnoses, and ambulatory

111 sensitive conditions were also analyzed as counts per person. We identified ED stress-responsive

112 diagnoses through literature review and expert opinion. Diagnoses included were agreed upon by

113 research team consensus and included 27 ICD-10 codes for acute coronary syndrome, assault,

114 suicide attempt, and syncope (Table S2). ${ }^{10,14,17-25}$ Ambulatory sensitive conditions are conditions

115 responsive to social stressors and inequalities for which an ED visit or hospitalization is

116 considered preventable through outpatient interventions. ${ }^{24,26}$ Ambulatory sensitive diagnoses

117 included 21 ICD-10 codes for: angina, asthma, congestive heart failure, chronic obstructive

118 pulmonary disease, diabetes complications, and hypertension (Table S2). ${ }^{24,26}$

120 Data

121 All patient demographic, visit, and diagnosis data were extracted from the HealthPartners

122 EHR by a HealthPartners Data Analyst. All records were de-identified and assigned a unique

123 Study ID prior to transfer through a secure file transmission system from HealthPartners to the

124 study team.

\section{Statistical Analyses}

127 We summarized the trends for each outcome using local linear regression and tested trend

128 similarity across groups prior to Order issuance using linear regression. For the difference-in-

129 difference analyses, we fit the linear regression model described in equation 1.

$130 Y=\beta_{0}+\beta_{1}$ OrderTargeted $+\beta_{2}$ OrderTargeted X Post Order $+\beta_{t}$ Period $+\varepsilon$ 
medRxiv preprint doi: https://doi.org/10.1101/2020.10.23.20218628; this version posted October 28, 2020. The copyright holder for this preprint (which was not certified by peer review) is the author/funder, who has granted medRxiv a license to display the preprint in perpetuity.

It is made available under a CC-BY-NC-ND 4.0 International license.

We compared the 360-days before and after Order issuance, divided into 24 distinct, 30-day time periods. Each outcome "Y" is a count per person per 30-day time period. "Order Targeted"

133 and "Order Targeted x Post Order" represent being from a nation named in the Order and being

134 from one of these nations in a time period after the Order was issued, respectively. For each

135 model, we also estimated the average effect $\left(\beta_{2}\right)$ over increasing time intervals centered on the

136 Order issuance date, beginning with 30-days pre- and post-Order and increasing by 30-day

137 increments to 360-days pre- and post-Order.

138 To further control for potentially confounding effects of individual characteristics and 139 temporal trends, we estimated the average effects relative to two alternative reference groups.

140 First, we used exact matching on age, sex, race, and insurance to reweight members of Group 3

141 (non-Latinx, U.S. born) and identify a subset of Group 3 with similar demographics as Group 1

142 (Order-targeted). We used the R package MatchIt to identify this reference group, then fit a

143 weighted version of the model described in equation 1 (Table S8). ${ }^{27}$ Second, we used a

144 generalized synthetical control method to reweight members of Group 3 to produce a reference

145 group with demographics and pre-Order outcomes more similar to those observed in Group 1.

146 Models were fit using the R package gsynth with parametric bootstrap standard errors. ${ }^{28}$

147 We fit separate models for all outcomes: primary care visits, missed primary care

148 appointments, primary care stress-responsive diagnoses, ED visits, and ED stress-responsive

149 diagnoses. The primary difference-in-difference analyses estimated the change in outcomes

150 between pre- and post-Order periods among individuals from Order-targeted nations above and

151 beyond the change observed among non-Latinx U.S.-born individuals. To determine whether

152 these differences are due to the Order, rather than other time-varying differences, we assumed

153 that the trends would have been equivalent across groups if the order had not been issued. We 
154 tested for parallel trends in the pre-intervention period by examining the interaction between

155 study group and time (30-day periods) in linear regression models. Our main results include

156 difference-in-difference estimates of the effect of the Order for outcomes with outcomes that did

157 not violate the parallel trends assumption prior to Order issuance. All estimates and robustness

158 checks are reported in the Supplement.

\section{RESULTS}

\section{Characteristics of Study Population}

162 From 2016 to $2017,252,594$ patients were included in this analysis: 5,667 (2.2\%) in Group 1,

$1631,254(0.5 \%)$ in Group 2, and 245,673 (97.3\%) in Group 3 (Table 1). People in Group 1 (from

164 Order-targeted nations) were predominantly Black $(92.3 \%, 5,233 / 5,667)$, female $(59.4 \%$,

$1653,367 / 5,667), 25-44$ years of age (62.3\%, 3,534/5,667), and had Medicare or Medicaid (78.1\%,

$1664,428 / 5,667)$. The largest proportion of Group 2 (non-Order-targeted Muslim-majority nations)

167 identified as white $(31.2 \%, 391 / 1,254)$ and $22-54$ years of age $(69 \%, 865 / 1,254)$. Group 3 (U.S.-

168 born, non-Latinx) was predominantly white $(82.8 \%, 203,342 / 245,673)$, slightly more than half

169 were female $(54.5 \%$ 133,883/245,673), and had an older age distribution (Table 1$)$.

\section{Trends in healthcare utilization and diagnoses}

172 The Muslim Ban Order was issued during a period of political change and its implementation

173 did not occur on a single day. Characterizing visit and diagnosis trends is critical to

174 understanding the effects of the political environment during 2016 and 2017 and allows us to

175 assess for parallel trends prior to Order issuance. Figure 1 displays weekly average visit counts

176 per person for each group, along with a local linear (loess) approximation of the time trend. 
178 Primary Care Clinic Utilization. Average daily clinic visits and stress-responsive diagnoses

179 trends are similar across all three groups in early 2016 (Figure 1A, 1C). While visits and stress-

180 responsive diagnoses remained fairly constant for U.S.-born non-Latinx individuals (Group 3),

181 beginning in early 2016, they dramatically increased for individuals from Muslim majority

182 nations in both Groups 1 and 2 after the 2016 presidential election and before Order issuance

183 (Figure 1A, 1C). This increase, and therefore the absence of parallel trends in the pre-Order

184 period, means that difference-in-difference analysis cannot be used to identify the effects of the

185 Order on primary care visits and responsive diagnoses (Table S3, S4). Missed scheduled clinic

186 appointments do appear to follow parallel trends prior to Order issuance (Table S3, S4), and

187 difference-in-difference can be conducted.

Emergency Department Utilization. U.S.-born non-Latinx individuals have higher baseline ED

190 utilization and ED visits for stress-responsive diagnoses; however, trends are fairly similar for all

191 three groups prior to Order issuance. The rate of ED visits was mostly flat, while stress-

192 responsive diagnoses slightly increased during the year prior to the Order. Around the 2016

193 election, the rate of ED visits and stress-responsive diagnoses increased for individuals from

194 Order-targeted nations (Group 1) as well as individuals from other Muslim majority nations

195 (Group 2) before leveling off at a higher utilization rate in mid to late 2017.

197 Effect of the Muslim Ban Order on healthcare utilization and diagnoses

198 For the three outcomes with similar trends between study groups prior to Order issuance, we

199 used difference-in-difference analysis to estimate the effect of the Order (Table 2, Figure 2). 
medRxiv preprint doi: https://doi.org/10.1101/2020.10.23.20218628; this version posted October 28, 2020. The copyright holder for this preprint (which was not certified by peer review) is the author/funder, who has granted medRxiv a license to display the preprint in perpetuity.

It is made available under a CC-BY-NC-ND 4.0 International license .

200 Equivalent analysis is presented in the Supplement for all outcomes without parallel trends prior

201 to Order issuance.

202

203 Primary Care Clinic Utilization. In the year following issuance of the Muslim Ban Order,

204 Groups 1 and 2 had greater increases in rates of primary care visits than were seen in Group 3 or

205 either alternative reference group drawn from Group 3 (Tables S5, S7, S9). However, the rise in

206 clinic visits and stress-responsive diagnoses occurred before Order issuance. Rates of missed

207 appointments for Group 1 do not appear to have been affected by the Order (Table 2, Figure 2A),

208 although a slight positive effect is estimated for Group 2 (Table S14).

209

210 Emergency Department Utilization. In the year following Order issuance, there was an increase

211 in ED visits and ED stress-responsive diagnoses among individuals from Order-targeted nations

212 beyond the increase seen among U.S.-born non-Latinx individuals. (Table 2, Figure 2B). There

213 was an additional increase in ED stress-responsive diagnoses after issuance of the Order for

214 individuals from Order-targeted nations; however, the difference-in-differences estimate was not

215 statistically significant. Compared to the demographically matched reference group, the

216 estimated Order effect on the Order-targeted group was negative, but also not statistically

217 significant (Table 2, S7). Compared to the synthetic control, the estimate was larger and

218 statistically significant, but the confidence intervals overlap. These findings are consistent, but

219 together they do not provide strong evidence of an Order effect on stress-responsive ED

220 diagnoses in the year following the order. (Table 2). The estimated effects of the Muslim Ban

221 Order on ED utilization and stress-responsive diagnoses for individuals from nations not targeted

222 in the Order were also not statistically significant (Table S14). 
medRxiv preprint doi: https://doi.org/10.1101/2020.10.23.20218628; this version posted October 28, 2020. The copyright holder for this preprint (which was not certified by peer review) is the author/funder, who has granted medRxiv a license to display the preprint in perpetuity.

It is made available under a CC-BY-NC-ND 4.0 International license .

In contrast to the utilization trends in the primary care clinic, Group 1 ED visits and stress-

224 responsive diagnoses may have been more immediately impacted by the Muslim Ban Order.

225 Shortly after the Order is issued, in the first 30- to 60-days, difference-in-difference analysis

226 demonstrates large Order effects on ED visits (Figure 2B) and stress-responsive diagnoses

227 (Figure 2C). Both increase shortly after the Order was issued beyond the increase seen in Group

2283 , but is not statistically significant.

\section{DISCUSSION}

231 The Muslim Ban Order was a major U.S. policy change impacting the U.S. Refugee

232 Resettlement Program, designed to drastically reduce travel and immigration from Order-

233 targeted nations. After Order issuance, there was an immediate increase in ED visits and ED

234 visits for stress responsive diagnoses among people from Order-targeted nations. Clinic

235 utilization and stress-responsive diagnoses increased before Order issuance, most notably after

236 the 2016 presidential election. The Muslim Ban Order was not a discrete event, as it underwent

237 multiple court challenges and did not go into effect until June 26, 2018. Our findings, even for

238 outcomes which followed similar trends prior to Order issuance, likely reflect the elevated

239 cumulative stress due to multiple restrictive policies and an increasingly hostile climate toward

240 Muslim Americans and Muslim immigrants and refugees in the U.S. ${ }^{5-7}$

241 Although the estimated differences in utilization and stress-responsive diagnoses are

242 relatively small, they are average differences per person per 30-day period. In a large population,

243 small per-person averages can result in substantial population health changes. In addition to

244 averaging over time, difference estimates may mask heterogeneity in the effect of the Muslim

245 Ban Order on a study population with diverse sub-groups. Our retrospective design and use of 
EHR data limited our ability to identify different sub-groups, which may respond differently to

247 political stress. Individual-level factors, such as prior trauma, religion, acculturation, and sense

248 of belonging with one's ethnic group, can influence coping. ${ }^{22,29}$ Factors that may increase

249 susceptibility to stress which are not recorded in EHRs include duration of time in the U.S.,

250 whether time spent in a refugee camp, prior interactions with the U.S. immigration and/or

251 refugee administration, employment status, and whether someone is awaiting family

252 reunification.

253 Estimated effects of the Order may have been attenuated by factors specific to Minneapolis-

254 St. Paul that may not be present in other cities and states. Social capital, ethnic enclaves, and

255 local pro-immigrant policies are important protective factors in Minneapolis-St. Paul that may

256 mitigate the harms from federal policy changes like the Muslim Ban. These local characteristics

257 of Minneapolis-St. Paul have provided social support and promoted civic engagement amongst

258 Somalis living in Minneapolis_ paving the way for Minneapolis to elect its first Somali-

259 American City Council member in $2013^{30}$ and its first Somali-American state legislator Ilhan

260 Omar in $2018 .^{31}$ Social capital, or the ability to secure benefits through social networks and

261 social structures, like community associations or civic organizations, attenuates the negative

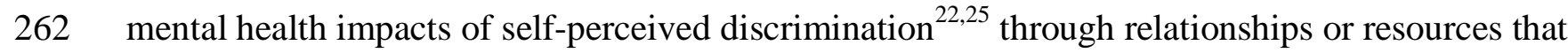

263 people mitigate the consequences of prejudice and discrimination. ${ }^{32}$ Ethnic enclaves, or

264 ethnically homogenous social groups, may also protect immigrants from discrimination and

265 related negative health effects. In one study assessing birth weight, residence in a Mexican

266 enclave attenuated risk of low birth weight for Mexican-origin mothers following the 2016

267 presidential election. ${ }^{23}$ A similar effect was demonstrated when Lauderdale et al's study on

268 birthweights among Arab Americans after September $11^{\text {th }}$ in California was replicated in 
269 Detroit. $^{8,11}$ The initial study demonstrated lower birthweights among Arab Americans following

270 September $11^{\text {th }}$, but this effect was not observed in Detroit, which has a large and strong Arab

271 American community. ${ }^{11}$

272 Research that aims to understand the impacts of immigration and refugee policy on Muslim

273 immigrants and refugees generally, and Muslim American immigrants and refugees in particular,

274 is limited by the lack of available population-level data. Furthermore, while the increases in

275 healthcare utilization may reflect increased community stress, this study does not directly

276 measure stress nor the relation between healthcare utilization and stress. Further investigations

277 are needed to determine this relation and potential mediators. It is important to consider that

278 healthcare utilization may not be the most sensitive population-level outcome to use as a proxy

279 measure for increased stress in immigrant communities. ${ }^{15,23}$ At baseline, immigrants tend to have

280 lower healthcare utilization compared to people born in the U.S., related to multiple factors

281 including service accessibility, prevalence of chronic illnesses, age, interpreter service

282 availability, cultural health beliefs, and comfort getting care within institutional medical

283 establishments. ${ }^{23,25}$ Furthermore, visiting a medical provider is one of many day-to-day activities,

284 such as school or work attendance, which may be sensitive to acute social stresses and warrant

285 further study.

286 There are several limitations to this study. First, evaluating the population-level health

287 impacts of the Muslim Ban Order on Muslim Americans is challenging, as most EHR and

288 healthcare data sources do not capture religious affiliation. As such, we used country of origin to

289 estimate Muslim American healthcare utilization. ${ }^{22,23,29}$ Other EHR limitations include data

290 about income and education, which are important factors noted to influence immigrant health

291 care utilization. ${ }^{33}$ Furthermore, when studying a small population, only relatively large effects 
292 are easily measured. This may result in an inability to detect small but important effects and

293 precludes nuanced analyses of utilization trends including direct comparison of individuals from

294 Muslim majority nations that were and were not targeted in the Order.

295 Second, we are limited in our ability to isolate the effects of the Order. Trends for two of our

296 primary outcomes, clinic visits and stress-responsive diagnoses, diverged in the year prior to the

297 Order issuance. Effects which could be estimated through a difference-in-difference analysis

298 may capture the cumulative effect of multiple events taking place around the time of Order

299 issuance and may not reflect its full impact over time. While we are examining changes in

300 utilization around a distinct event, the Order was issued seven days after President Trump's

301 Inauguration, following a campaign characterized by anti-immigrant and anti-Muslim rhetoric,

302 and it did not go into effect until June 2017. Therefore, we cannot distinguish which specific

303 event caused changes in utilization patterns.

304 Third, Muslim Americans living in and around Minneapolis-St. Paul are not a homogenous

305 group. Somali Americans, who are racialized as Black, therefore experiencing both racism and

306 anti-Muslim sentiment differently from Arab Muslim Americans racialized as white. This

307 analysis could not differentiate Order impact between these groups, and qualitative methods are

308 better suited to exploring intersectional identities. These and other important differences that are

309 not systematically captured in the EHR could influence the health impacts observed in this study,

310 including: immigration or refugee status, time since immigration, time spent in refugee camps,

311 and acculturation. This study also does not account for second generation immigrants who may

312 experience social and familial stress due to the Order, but be included in the U.S. born

313 comparison group, thereby reducing detected differences between study groups. 
314 Finally, the study group and location are not nationally representative of all groups targeted

315 by the Order, which limits generalizability of our findings. Minneapolis-St. Paul is a large,

316 diverse, urban area with comparatively strong social supports for refugees generally, and Somalis

317 in particular. In other locations with smaller refugee and/or immigration communities and fewer

318 social supports there may be larger negative effects of restrictive immigration and refugee

319 policies.

\section{Public Health Implications}

322 Increases in primary care utilization prior to issuance of the Order and in ED visits after

323 Order-issuance likely reflect elevated cumulative stress due to multiple factors rather than one

324 particular policy change. Further investigations are needed to evaluate whether increases in

325 utilization are driven by particular subgroups, identify protective factors that convey individual

326 and population-level resilience to political social stressors, and elucidate specific health effects

327 of restrictive immigration policies and cumulative social stress on Muslim Americans. 
medRxiv preprint doi: https://doi.org/10.1101/2020.10.23.20218628; this version posted October 28, 2020. The copyright holder for this preprint (which was not certified by peer review) is the author/funder, who has granted medRxiv a license to display the preprint in perpetuity.

\section{References}

1. Pierce S, Selee A. Immigration under Trump: A Review of Policy Shifts in the Year Since the Election. Washington, D.C.: Migration Policy Institute;2017.

2. Executive Order Protecting The Nation From Foreign Terrorist Entry Into The United States. https://www.whitehouse.gov/presidential-actions/executive-order-protectingnation-foreign-terrorist-entry-united-states-2/. Published March 6, 2017. Accessed December 1, 2019.

3. Trump vs Hawaii, (United States Supreme Court 2018).

4. Samari G. Islamophobia and Public Health in the United States. Am J Public Health. 2016;106(11):1920-1925.

5. Federal Bureau of Investigation. Hate Crime Statistics, 2018: Incidents and Offenses. https://ucr.fbi.gov/hate-crime/2018/topic-pages/incidents-and-offenses. Published 2018. Accessed December 15, 2019.

6. Council on American-Islamic Relations. Targeted: 2018 Civil Rights Report. Washington, D.C.: Council on American-Islamic Relations,;2018.

7. Southern Poverty Law Center. Ten Days After: Harassment and Intimidation in the Aftermath of the Election. https://www.splcenter.org/20161129/ten-days-afterharassment-and-intimidation-aftermath-election. Published November 29, 2016. Accessed December 29, 2019.

8. Lauderdale DS. Birth outcomes for Arabic-named women in California before and after September 11. Demography. 2006;43(1):185-201.

9. Padela AI, Heisler M. The Association of Perceived Abuse and Discrimination After September 11, 2001, With Psychological Distress, Level of Happiness, and Health Status Among Arab Americans. Am J Public Health. 2010;100(2):284-291.

10. Rousseau C, Hassan G, Moreau N, Thombs BD. Perceived discrimination and its association with psychological distress among newly arrived immigrants before and after September 11, 2001. Am J Public Health. 2011;101(5):909-915.

11. El-Sayed A, Hadley C, Galea S. Birth outcomes among Arab Americans in Michigan before and after the terrorist attacks of September 11, 2001. Ethn Dis. 2009;18(3):348356.

12. Centers for Disease Control and Prevention. Refugee Health Profiles: Somali Refugees. Centers for Disease Control and Prevention,. https://www.cdc.gov/immigrantrefugeehealth/profiles/somali/populationMovements.html . Published 2018. Accessed December 1, 2019.

13. Data USA. DATA USA: Minneapolis-S.Paul-Bloomington,MN-WI. https://datausa.io/profile/geo/minneapolis-st.-paul-bloomington-mn-wi-metroarea\#demographics. Published August 2020. Accessed August 6, 2020.

14. Hatzenbuehler ML, Prins SJ, Flake M, et al. Immigration policies and mental health morbidity among Latinos: A state-level analysis. Soc Sci Med. 2017;174:169-178.

15. Toomey RB, Umana-Taylor AJ, Williams DR, Harvey-Mendoza E, Jahromi LB, Updegraff KA. Impact of Arizona's SB 1070 immigration law on utilization of health care and public assistance among Mexican-origin adolescent mothers and their mother figures. Am J Public Health. 2014;104 Suppl 1:S28-34. 
medRxiv preprint doi: https://doi.org/10.1101/2020.10.23.20218628; this version posted October 28, 2020. The copyright holder for this preprint (which was not certified by peer review) is the author/funder, who has granted medRxiv a license to display the preprint in perpetuity. It is made available under a CC-BY-NC-ND 4.0 International license .

16. von Elm E, Altman DG, Egger M, et al. The Strengthening the Reporting of Observational Studies in Epidemiology (STROBE) statement: guidelines for reporting observational studies. PLoS Med. 2007;4(10):e296.

17. Finnstrom B, Soderhamn O. Conceptions of pain among Somali women. J Adv Nurs. 2006;54(4):418-425.

18. Jager KS. Addressing Mental Health with the Somali Population in the Twin Cities Area. Master of Social Work Clinical Research Papers. 2014:Paper 333.

19. Kessler RC, Mickelson KD, Williams DR. The prevalence, distribution, and mental health correlates of perceived discrimination in the United States. J Health Soc Behav. 1999;40(3):208-230.

20. Moradi B, Hasan NT. Arab American persons' reported experiences of discrimination and mental health: The mediating role of personal control. J Couns Psychol. 2004;51(4):418.

21. Pavlish CL, Noor S, Brandt J. Somali immigrant women and the American health care system: discordant beliefs, divergent expectations, and silent worries. Soc Sci Med. 2010;71(2):353-361.

22. Rippy AE, Newman E. Perceived Religious Discrimination and its Relationship to Anxiety and Paranoia Among Muslim Americans. Journal of Muslim Mental Health. 2006;1(1):5-20.

23. Williams DR, Medlock MM. Health Effects of Dramatic Societal Events - Ramifications of the Recent Presidential Election. N Engl J Med. 2017;376(23):2295-2299.

24. Sanderson C, Dixon J. Conditions for which onset or hospital admission is potentially preventable by timely and effective ambulatory care. J Health Serv Res Policy. 2000;5(4):222-230.

25. Stalnikowicz R, Tsafrir A. Acute psychosocial stress and cardiovascular events. Am J Emerg Med. 2002;20(5):488-491.

26. Agency for Healthcare Research and Quality. Guide to prevention quality indicators: hospital admission for ambulatory care sensitive conditions. Rockville, MD: Agency for Healthcare Research and Quality;2001.

27. Ho DE, Imai K, King G, Stuart EA. MatchIt: Nonparametric Preprocessing for Parametric Causal Inference. Journal of Statistical Software. 2011;42(8).

28. Xu Y. Generalized Synthetic Control Method: Causal Inference with Interactive Fixed Effects Models. Political Analysis. 2017;25(1):57-76.

29. Padela AI, Raza A. American Muslim health disparities: the state of the Medline literature. J Health Disparities Res Pract. 2015;8(1).

30. Rao M. First Somali elected to Mpls. City Council. Star Tribune. https://www.startribune.com/first-somali-elected-to-mpls-city-council/230761041/. Published November 6, 2013. Accessed August 18, 2020.

31. Golden E. Ilhan Omar again makes history, becoming 1st Somali-American elected to U.S. House. Star Tribune. https://www.startribune.com/ilhan-omar-becomes-first-somaliamerican-elected-u-s-house/499708271/. Published November 7, 2018. Accessed August 18, 2020.

32. Fazel M, Reed RV, Panter-Brick C, Stein A. Mental health of displaced and refugee children resettled in high-income countries: risk and protective factors. The Lancet. 2012;379(9812):266-282. 
medRxiv preprint doi: https://doi.org/10.1101/2020.10.23.20218628; this version posted October 28, 2020. The copyright holder for this preprint (which was not certified by peer review) is the author/funder, who has granted medRxiv a license to display the preprint in perpetuity.

It is made available under a CC-BY-NC-ND 4.0 International license .

33. Sarria-Santamera A, Hijas-Gomez AI, Carmona R, Gimeno-Feliu LA. A systematic review of the use of health services by immigrants and native populations. Public Health Rev. 2016;37:28.

Table 1. Characteristics of HealthPartners patients seeking care in a primary care clinic or emergency department, January 2016 to December 2017

\begin{tabular}{|c|c|c|}
\hline $\begin{array}{l}\text { Group } 1 \\
\text { People born in a } \\
\text { Muslim Ban Order } \\
\text { targeted nation }^{1} \\
(\mathrm{n}=5,667) \\
\text { No. }(\%)\end{array}$ & $\begin{array}{l}\text { Group } 2 \\
\text { People born in a } \\
\text { Muslim-majority } \\
\text { nation not named in } \\
\text { the Muslim Ban } \\
\text { Order } \\
(\mathrm{n}=1,254) \\
\text { No. }(\%)\end{array}$ & $\begin{array}{l}\text { Group } 3 \\
\text { U.S.-born, non-Latinx } \\
(\mathrm{n}=245,673) \\
\text { No. }(\%)\end{array}$ \\
\hline
\end{tabular}

\section{Race}

American

Indian/Alaska

Native

Asian

$10(0.2)$

$12(1)$

$3207(1.3)$

Black

$45(0.8)$

$307(24.5)$

$5,567(2.3)$

Native

$5,233(92.3)$

$272(21.7)$

$29,644(12.1)$

Hawaiian/Pacific $\quad 5(0.1)$

$11(0.9)$

$660(0.3)$

Islander

White

$155(2.7)$

$391(31.2)$

$203,342(82.8)$

\section{Sex}

Female

$3,367(59.4)$

$627(50)$

$133,883(54.5)$

Male

$2,300(40.6)$

$627(50)$

$111,786(45.5)$

\section{Age}

18-24

$498(8.8)$

$105(8.4)$

24,747 (10.1)

25-34

$2,076(36.6)$

$283(22.6)$

49,897 (20.3)

$35-44$

$1,458(25.7)$

$311(24.8)$

40,385 (16.4)

45-54

927 (16.4)

$271(21.6)$

44,007 (17.9)

55-64

$520(9.2)$

175 (14)

49,107 (20)

$\geq 65$

408 (7.2)

$172(13.7)$

46,586 (19)

\section{Insurance status}

Commercial

995 (17.6)

622 (49.6)

145,161 (59.1)

Medicare or Medicaid

4,428 (78.1)

$574(45.8)$

91,253 (37.1)

* Missing or unknown data not included in table; sums may not add to $100 \%$

${ }^{2}$ Afghanistan, Albania, Algeria, Azerbaijan, Bahrain, Bangladesh, Bosnia-Herzegovnia, Brunei, Burkina Faso, Chad, Cocos Islands, Djibouti, Egypt, Gambia, Guinea, Indonesia, Jordan, Kazakhstan, Kosovo, Kuwait, Kyrgyzstan, Lebanon, Malaysia, Maldives, Mali, Mauritania, Mayotte, Morocco, Niger, Oman, Pakistan, Palestine, Qatar, Saudi Arabia, 
medRxiv preprint doi: https://doi.org/10.1101/2020.10.23.20218628; this version posted October 28, 2020. The copyright holder for this preprint (which was not certified by peer review) is the author/funder, who has granted medRxiv a license to display the preprint in perpetuity.

It is made available under a CC-BY-NC-ND 4.0 International license .

Table 2: Difference-in-difference estimates of the effect of the Muslim Ban Order on missed primary care clinic appointments, emergency department visits, and emergency department stress-responsive diagnoses among patients from Order-targeted nations

\begin{tabular}{|c|c|c|c|c|c|c|}
\hline & \multicolumn{4}{|c|}{ Difference in Differences Model } & \multirow{2}{*}{$\begin{array}{l}\text { Matched } \\
\text { Difference in } \\
\text { Differences } \\
\text { Model } \\
\text { Estimate } \\
\text { (SE) }\end{array}$} & \multirow[b]{2}{*}{$\begin{array}{l}\text { Generalized } \\
\text { Synthetic } \\
\text { Control Model } \\
\text { Estimate } \\
\text { (SE) }\end{array}$} \\
\hline $\begin{array}{l}\text { Outcome } \\
\text { (average per } \\
\text { person) }\end{array}$ & Means & $\begin{array}{l}\text { U.S.- } \\
\text { born, } \\
\text { non- } \\
\text { Latinx }\end{array}$ & $\begin{array}{l}\text { Order- } \\
\text { Targeted }\end{array}$ & $\begin{array}{l}\text { Difference in } \\
\text { Differences } \\
\text { Estimate } \\
\text { (SE) }\end{array}$ & & \\
\hline \multirow{3}{*}{$\begin{array}{l}\text { Missed } \\
\text { primary care } \\
\text { appointments } \\
\mathrm{N}=152,505\end{array}$} & Pre-Order & 0.029 & 0.046 & \multirow{3}{*}{$\begin{array}{l}\mathbf{0 . 0 0 2} \\
(0.001)\end{array}$} & \multirow{3}{*}{$\begin{array}{l}\mathbf{0 . 0 0 3} \\
(0.002)\end{array}$} & \multirow{3}{*}{$\begin{array}{l}\mathbf{0 . 0 0 2} \\
(0.001)\end{array}$} \\
\hline & Post- Order & 0.029 & 0.048 & & & \\
\hline & $\begin{array}{l}\text { First } \\
\text { Difference }\end{array}$ & 0.000 & 0.002 & & & \\
\hline \multirow{3}{*}{$\begin{array}{l}\text { ED visits per } \\
\text { person } \\
N=112,220\end{array}$} & Pre- Order & 0.032 & 0.021 & \multirow{3}{*}{$\begin{array}{l}\mathbf{0 . 0 0 4} \\
(0.001)\end{array}$} & \multirow{3}{*}{$\begin{array}{l}\mathbf{0 . 0 0 5} \\
(0.002)\end{array}$} & \multirow{3}{*}{$\begin{array}{l}\mathbf{0 . 0 0 4} \\
(0.003)\end{array}$} \\
\hline & Post- Order & 0.033 & 0.026 & & & \\
\hline & $\begin{array}{l}\text { First } \\
\text { Difference }\end{array}$ & 0.001 & 0.005 & & & \\
\hline \multirow{3}{*}{$\begin{array}{l}\text { ED } \\
\text { ambulatory } \\
\text { sensitive and } \\
\text { acute stress } \\
\text { diagnoses } \\
\mathrm{N}=31,861\end{array}$} & Pre- Order & 0.119 & 0.064 & \multirow[b]{3}{*}{$\begin{array}{l}\mathbf{0 . 0 0 5} \\
(0.005)\end{array}$} & \multirow[b]{3}{*}{$\begin{array}{l}\mathbf{- 0 . 0 0 4} \\
(0.007)\end{array}$} & \multirow[b]{3}{*}{$\begin{array}{l}\mathbf{0 . 0 1 9} \\
(0.006)\end{array}$} \\
\hline & Post- Order & 0.133 & 0.083 & & & \\
\hline & $\begin{array}{l}\text { First } \\
\text { Difference }\end{array}$ & 0.014 & 0.019 & & & \\
\hline
\end{tabular}

Table 2: Effect estimates are additional increases in each outcome (per person per 30-day time period) from the year before to the year after the Muslim Ban Order was issued among individuals from Order-targeted nations, beyond the increases observed in a reference group. Each outcome is displayed on a separate row. Robust standard errors are included in parentheses for difference in difference estimates with and without demographic matching. Parametric bootstrap standard errors are included in parentheses for generalized synthetical control model 


\section{Figure 1: Time trends for all primary outcomes among patients from Order-targeted nations, patients from other Muslim-majority nations, and U.S.-born non-Latinx patients, January 2016 to December 2017.}
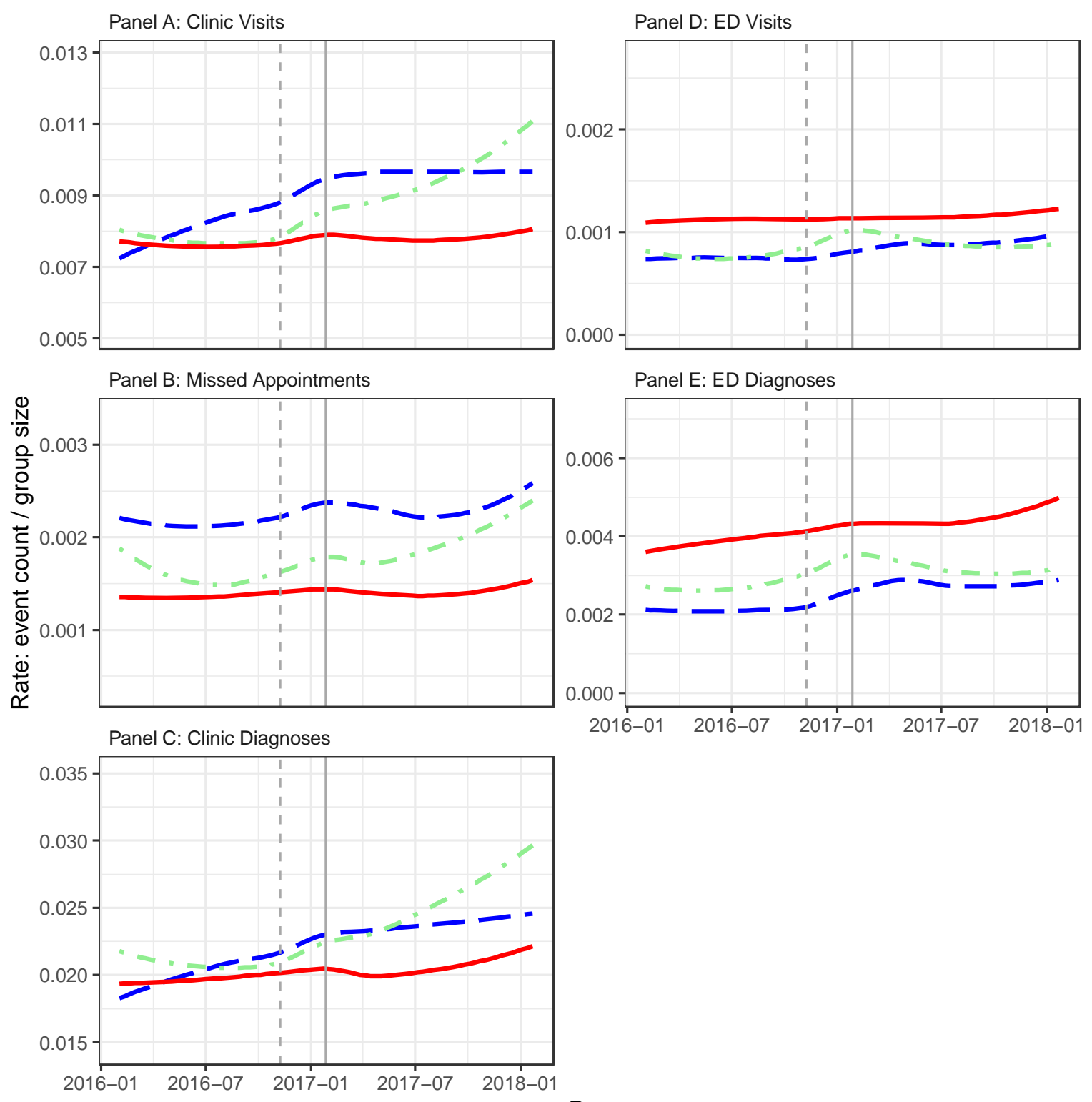

Figure 1: Points indicate weekly average counts per person in each group for A) clinic visits, B) missed clinic appointments, C) clinic stress-responsive diagnoses, D) ED visits, and E) ED stress-responsive diagnoses. A loess regression line summarizing the time trend is included for each group, based on daily average counts per person. For all clinic outcomes, panels A, B, and $\mathrm{C}$, non-business days are excluded from the analysis. The solid line marks the Order issuance 464 and the dotted line marks the 2016 election, for reference. 

ED stress-responsive diagnoses, January 2016 to December 2017.

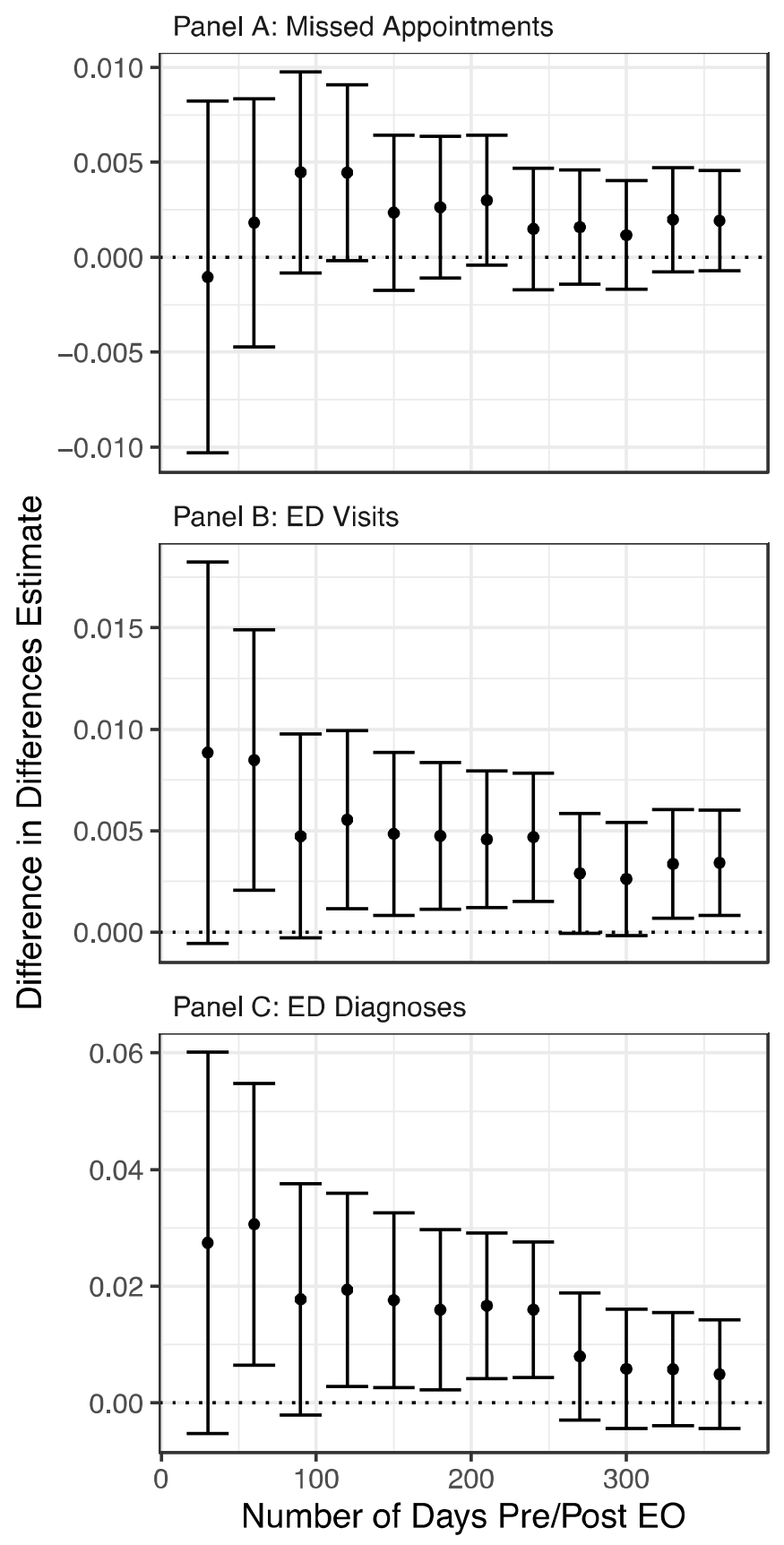

Figure 2: Each point represents a difference-in-differences estimate of the effect of the Muslim a 95\% confidence interval. The left most points compare the difference in each outcome 30 days before to 30 days after the issuance of the Order for Groups 1 and 3. Each additional point compares differences across a larger time period up to 360 days pre-/post-Order. 